\title{
Assessment of the Potential of Offshore Wind Energy in Taiwan using Fuzzy Analytic Hierarchy Process
}

\author{
Tsung-Lin Lee*
}

Institute of Asset Management and Urban Planning, Leader University, Tainan 709, Taiwan, ROC

\begin{abstract}
In this paper, the application of the Fuzzy Analytic Hierarchy Process (Fuzzy AHP) combined with a set of criteria analysis for the selection of appropriate sites for the development offshore wind energy in Taiwan is presented. The Fuzzy AHP was first conducted to rank the importance and identify the key factors of offshore wind energy successfully. From the numerical results, eight key factors that must be considered in the site selection of offshore wind energy system in Taiwan were obtained by using Fuzzy AHP model. They are: wind power, earthquakes, land use, shore type, typhoon, distance to shoreline, flight safety and water depth. Based on these factors, a set of criteria for the selection of sites for offshore wind farms was also established using five different sites in Taiwan. From the assessment results, it was found that Changhua coastal region is an appropriate site for offshore wind energy in Taiwan.
\end{abstract}

Keywords: Fuzzy analytic hierarchy process, offshore wind energy, typhoon, earthquake.

\section{INTRODUCTION}

For a rapidly industrializing island society such as Taiwan, sustainable energy utilization faces numerous challenges at the beginning of the 21 st century. In the past, $97 \%$ of energy supply is imported fossil fuels and uranium in Taiwan. Therefore, fluctuations of international energy prices and availability of imported energy supplies significantly affect domestic socio-economic stability. Furthermore, the expanding use of fossil fuels due to economic development has resulted in rapidly increasing $\mathrm{CO}_{2}$ emissions, which has been the main contribution to the global climate change.

The utilizations of wind energy have been growing dramatically throughout the world. Over the past two decades, on-shore wind energy technology has been intensively studied. While on-shore wind technology becomes mature, offshore wind energy still at the beginning stage. Offshore wind systems (OWES) are different from on-shore installations for several reasons. Despite of the high cost compared with on-shore wind farms, but OWES are commonly built several kilometers away from the coast, OWES have some advantages, such as huge energy resources due to the higher average wind speeds and the reduction of the sitting and environmental issues, particularly with regards to noise, visual constraints and space limitations [1-3].

Taiwan is a small island which has scarce energy and resources. 97\% of the energy consumption in Taiwan is imported. Due to the crude oil price increase, the total import

*Address correspondence to this author at the No. 188 , Sec. 5, An-Chung Rd., Tainan City, 709, Taiwan, R.O.C.; Tel: +886-6-2552500 ext 32000; Fax: +886-6-2553225;

E-mails: tllee@mail.leader.edu.tw,dr.tllee@msa.hinet.net cost of energy has increased $33.6 \%$ from 2004 to 2005. As reported in Taiwan Energy Policy Whitepaper [4], to achieve sustainable development targets in the future, the future development strategies of energy have been developed:

1. to facilitate the promotion and utilization of non-carbon renewable energy;

2. to expand the utilization of low carbon (LNG) clean energy;

3. to adopt high efficiency power generating equipment;

4. to promote co-generation system;

5. to improve transmission line loss, to conserve energy and raise energy utilization efficiency;

6. to rationalize energy price; and

7. to facilitate an adjustment in industrial structure.

In Taiwan, the target for installed capacity of renewable energy has been set as $10 \%$ of total installed capacity by 2010. Therefore, development of renewable energy has great potential in Taiwan.

Wind energy is a kind of energy resources that will have continuous supply with minimum pollution onto the earth. Taiwanese government started to promote the application of wind power aggressively since 2000. By 2007, there are 127 wind power turbines on shore with $630 \mathrm{MW}$ in total capacity in Taiwan. The target of 2,159 MW (including $360 \mathrm{MW}$ of offshore wind power) for wind power by 2010 has been set by MOEA in 2004 [5]. In the future, offshore capacity will be expect to provide 300 400 MW per year after 2010. Since Taiwan is an island surrounded by the Pacific Ocean, the development of offshore wind energy has great potential, comparing with other renewable energy resources. 
Most offshore wind farms have been installed in Northern Europe, in particularly Denmark and UK [3]. The assessments for offshore wind farms with mono-piles in shallow water will be proposed in Australia [6, 7]. To date, no offshore wind system has been installed in Taiwan, even though renewable energy has been identify as one of research priorities in Taiwan academics. Therefore, it is necessary to establish an effective tool for the assessment of potential sites of offshore wind farms in Taiwan before starting a detailed design of wind farm structures.

In this paper, we will apply Fuzzy Analytic Hierarchy Process (Fuzzy AHP) to identify dominant factors involved in the site selection of offshore wind farms in Taiwan. Therefore, an assessment on possible several sites for the development of OWES, where have been considered by Taiwanese government, will be conducted. With the proposed model, an appropriate site for the development of the OWES in Taiwan will be suggested.

\section{FUZZY ANALYTIC HIERARCHY PROCESS}

The Analytic Hierarchy Process (AHP) developed by Saaty [8] has been widely used for multi-criteria decisionmaking and practical decision-making problems [9]. In spite of its popularity, this method has been criticized for its inability to adequately handle the inherent uncertainty and imprecision associated with the mapping of the decisionmaker's perception to exact numbers [10]. In the conventional formulation of the AHP, human's judgments are represented as exact numbers (or crisp, according to the fuzzy logic terminology). However, in many practical cases the human preference model is uncertain. Thus, decision-makers might be reluctant or unable to assign exact numerical values to the comparison judgments. Therefore, a Fuzzy Analytic Hierarchy Process (Fuzzy AHP) is used on each factor to determine the weight of fuzziness of its attributes. Herein, we apply the Fuzzy AHP to find the importance sequence and identify the key success factors for the selection of appropriate OWES sites in Taiwan.

In the problem of decision making, the following main steps are taken for the AHP:

1. Problem hierarchically structuring: The AHP decision problem is structured hierarchically at different levels. Each level consists of a finite number of decision elements. The top level of the hierarchy represents the overall goal, while the lowest level is composed of all possible alternatives. One or more intermediate levels embody the decision criteria and sub-criteria.

2. Development of judgment matrices by pair-wise comparisons: The judgment matrices of criteria or alternatives can be defined from the reciprocal comparisons of criteria at the same level or all possible alternatives. Pairwise comparisons are based on a standardized evaluation schemes from 1 to 9 .

3. Assessment of global priorities: Several methods for deriving local priorities (i.e. the local weights of criteria and the local scores of alternatives) from judgment matrices have been developed, such as the eigenvector method (EVM), the logarithmic least squares method (LLSM), the weighted least squares method (WLSM), the goal programming method (GPM) and the fuzzy programming method (FPM), as summarized by Mikhailov [11]. Consistency check should be implemented for each judgment matrix.

4. Calculation of global priorities: The last step of the AHP aggregates all local priorities from the decision table by a simple weighted sum. The global priorities thus obtained are used for final ranking of the alternatives and selection of the best one.

In this study the triangular fuzzy numbers will be adopted. A triangular fuzzy number $\tilde{N}$ is defined by three real numbers $(\ell \leq m \leq u)$, and characterised by a linear piecewise continuous membership function $\mu_{\tilde{N}}(x)$ of the type.

$$
\mu_{\tilde{N}}(x)= \begin{cases}(x-\ell) /(m-\ell) & , \ell \leq x \leq m \\ (u-x) /(u-m) & , m \leq x \leq u \\ 0 & , \text { otherwise }\end{cases}
$$

where $l, m$ and $u$ are also considered as the lower bound, the mean bound, and the upper bound, respectively. The fuzzy number $\tilde{N}$ is often expressed as a triplet $(l, m, u)$.

After pair-wise comparisons are finished at a level, a fuzzy reciprocal judgment matrix $\tilde{A}$ can be established as.

$\tilde{A}=\left[\begin{array}{cccc}1 & \tilde{a}_{12} & \ldots & \tilde{a}_{1 n} \\ \tilde{a}_{12} & 1 & \ldots & \tilde{a}_{2 n} \\ : & : & . & : \\ \tilde{a}_{n 1} & \tilde{a}_{n 2} & \ldots & 1\end{array}\right]$

in which $n$ is the number of the related elements at this level and $\tilde{a}_{j i}=1 / \tilde{a}_{i j}$.

After constructing $\tilde{A}$, we use the fuzzy geometric means [12] to derive fuzzy priorities $\tilde{w}_{i}, i=1,2, \ldots, n$, in this paper. Finally, the global priorities expressed as fuzzy numbers can be determined by aggregating fuzzy local priorities in the following:

$\bar{W}=\prod_{i=1}^{n} \overline{W_{i}}$

where $n$ is the number of level and $\prod_{i=1}^{n} \bar{W}_{i}$ is the product of weights for all levels.

\section{CONCEPTUAL MODEL FOR THE SELECTION OF OWES SITES}

A conceptual model of offshore wind energy for the selection of appropriate sites is established on the basis of the Delphi method and the Fuzzy AHP method. In this study, we use Taiwan as a case study domain to show how the proposed conceptual model is applied to the selection of OWES 
sites. In general, there are many factors that directly affect the selection of sites for offshore wind energy systems in Taiwan regions, including global and local parameters.

Four main criteria have been chosen for evaluation of offshore wind energy, namely Weather and marine meteorology, Geology and topography, Locations and proposed area and Human behavior and ecological protection, and each main criterion is additionally divided into four sub-criteria, namely Typhoon, Thundershower, Temperature, Tide, Wind power, Geology, Shore type, Earthquake, Water depth, Distance to shoreline, Proposed area, Land use, Shipping activities, Flight safety, Ecological protection and Fish resource. The goal here is to select the key factors of offshore wind energy, satisfying all criteria in the best way.

The solution process is based on the proposed fuzzy modification of the AHP method. The first step in applying the fuzzy AHP is to construct a (four level) hierarchy of offshore wind energy and criteria for choice, as shown on Fig. (1).

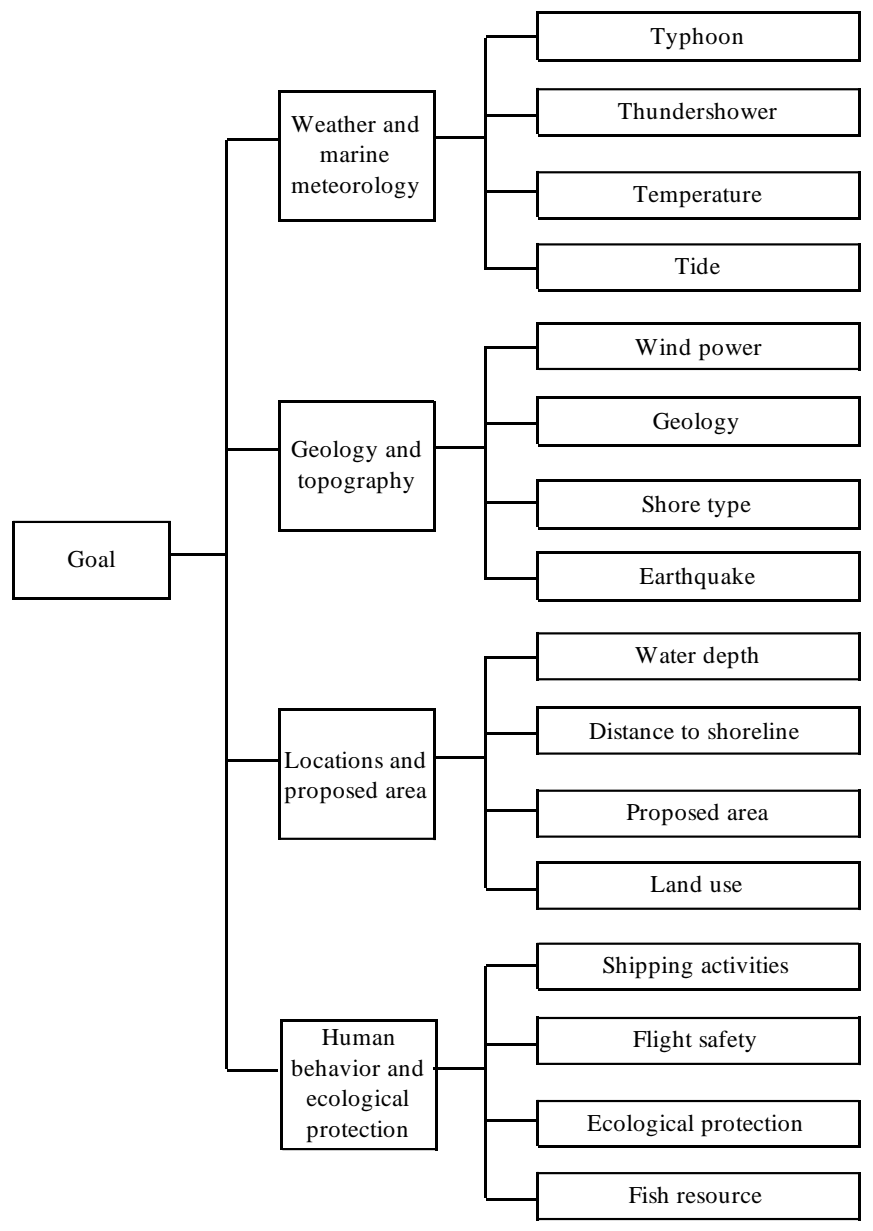

Fig. (1). Decision hierarchy.

An important consideration in terms of the quality of the ultimate decision relates to the consistency of judgments that the decision maker demonstrated during the series of pairwise comparisons. The consistency ratio (C.R.) is a measure of the consistency of pair-wise comparison judgments, which measure the degree of consistency among the pair-wise judgments provided by the decision maker. If the degree of consistency is acceptable, the decision process can be continued. On the other hand, if the degree of consistency is unacceptable, the decision maker should reconsider and possibly revise the pair-wise comparison judgments before processing the analysis. In general, the ratio is designed in such a way that values of the ratio exceeding 0.10 are indicative of inconsistent judgments. The C.R. is estimated as the following:

Step 1: Multiply each value in the first column of the pairwise comparison matrix by the relative priority of the first item considered. Same procedures will be applied to other items. Sum the values across the rows to obtain a vector of values labeled "weighted sum".

Step 2: Divide the elements of the vector of weighted sums obtained in Step 1 by the corresponding priority value.

Step 3: Compute the average of the values computed in Step 2 . The $\lambda_{\max }$ is maximum Eigen value of the comparison matrix.

Step 4: Compute the consistency index (C.I.):

$$
\text { C.I. }=\frac{\lambda_{\text {max }}-n}{n-1}
$$

where $n$ is the number of items.

Step 5: Compute the consistency ratio (C.R.):

$$
\text { C.R. }=\frac{\text { C.I. }}{R . I .}
$$

where R.I. is the random index, which is the consistency index of a randomly generated pair-wise comparison matrix.

The fuzzy comparison judgments of the four main criteria with respect to the overall goal are shown in Table $\mathbf{1}$. Geology and topography are regarded as the most important criterion, evaluated as being between five times more important than Weather and marine meteorology, about two times more important than Locations and proposed area, and about seven times more important than Human behavior and ecological protection. Utilizing the fuzzy prioritization method, the exact weights and the average of $\lambda_{\max }$ of main criteria are obtained as shown in Table $\mathbf{2}$. As shown in Table 2, the value of the consistency index (C.I.) is 0.07 and the consistency ratio $(C . R$.) is 0.08 . Both C.I. and R.I. values are much smaller than 1 , which indicates that the degree of consistency is acceptable. The fuzzy weights of the comparison judgments regarding the goal are also shown in Fig. (2). From the figure, geology and topography is assessed as the more important issues than locations and proposed area, weather and marine meteorology, human behavior and ecological protection. Therefore, the geology and topography are considered as the most important criterion, since all fuzzy weight is greater than other factors. All sub-criteria are compared at the second level in terms of corresponding main criteria, and the related fuzzy comparison matrices are constructed in Tables 3. By using the same prioritization method, 
Table 1. Fuzzy Comparison Matrices at the First Level

\begin{tabular}{|c|c|c|c|c|}
\hline Goal & $\begin{array}{c}\text { Weather and } \\
\text { Marine Meteorology }\end{array}$ & $\begin{array}{c}\text { Geology and } \\
\text { Topography }\end{array}$ & $\begin{array}{c}\text { Locations and } \\
\text { Proposed Area }\end{array}$ & $\begin{array}{c}\text { Human Behavior and } \\
\text { Ecological Protection }\end{array}$ \\
\hline \hline Weather and marine meteorology & $(1,1,1)$ & $(1 / 5,1 / 4,1 / 3)$ & $(1 / 5,1 / 4,1 / 3)$ & $(1,2,3)$ \\
\hline Geology and topography & $(3,4,5)$ & $(1,1,1)$ & $(3,4,5)$ & $(5,6,7)$ \\
\hline Locations and proposed area & $(3,4,5)$ & $(1 / 5,1 / 4,1 / 3)$ & $(1,1,1)$ & $(1,3,5)$ \\
\hline Human behavior and ecological protection & $(1 / 3,1 / 2,1)$ & $(1 / 7,1 / 6,1 / 5)$ & $(1 / 5,1 / 3,1)$ & $(1,1,1)$ \\
\hline
\end{tabular}

Table 2. The Weight and $\lambda$ Value of Main Criteria

\begin{tabular}{|c|c|c|}
\hline Goal & Weights & $\lambda$ Value \\
\hline \hline Weather and marine meteorology & w1 $=0.11$ & 4.25 \\
\hline Geology and topography & w2 $=0.57$ & 4.23 \\
\hline Locations and proposed area & w3 $=0.23$ & 4.33 \\
\hline Human behavior and ecological protection & w4 $=0.08$ & 4.09 \\
\hline
\end{tabular}

$\lambda_{\max }=4.22 ;$ C.I. $=\left(\lambda_{\max }-n\right) /(n-1)=0.07 ;$ C.R. $=$ C.I. $/$ R.I. $=0.08$.

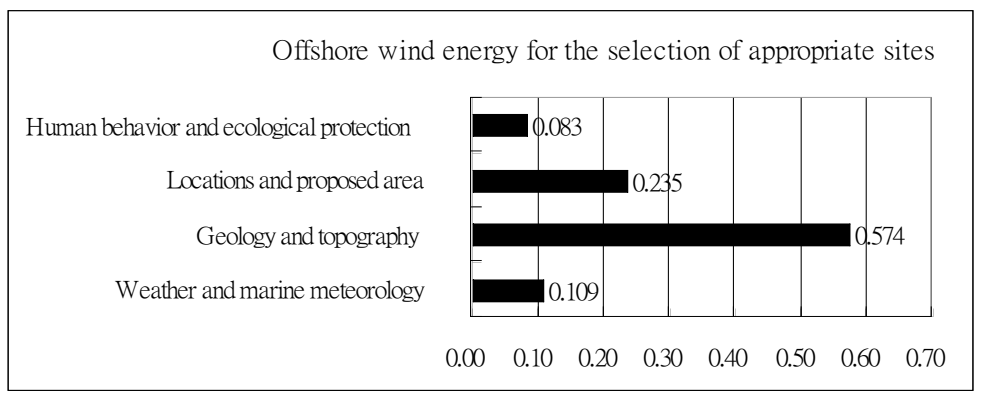

Fig. (2). Fuzzy weight of the pair-wise comparisons in the main criteria.

Table 3. Fuzzy Comparison Matrices at the Second Level for Weather and Marine Meteorology, Geology and Topography, Locations and Proposed Area and Human Behavior and Ecological Protection

\begin{tabular}{|c|c|c|c|c|}
\hline Goal & Typhoon & Thundershower & Temperature & Tide \\
\hline Thundershower & $(1 / 5,1 / 4,1 / 3)$ & $(1,1,1)$ & $(1 / 5,1 / 3,1)$ & $(1,2,3)$ \\
\hline Temperature & $(1 / 5,1 / 4,1 / 3)$ & $(1,3,5)$ & $(1,1,1)$ & $(1,3,5)$ \\
\hline Tide & $(1 / 5,1 / 4,1 / 3)$ & $(1 / 3,1 / 2,1)$ & $(1 / 5,1 / 3,1)$ & $(1,1,1)$ \\
\hline Wind power & $(1,1,1)$ & $(5,6,7)$ & $(3,4,5)$ & $3,4,5$ \\
\hline Geology & $(1 / 7,1 / 6,1 / 5)$ & $(1,1,1)$ & $(1 / 5,1 / 3,1)$ & $(1 / 5,1 / 4,1 / 3)$ \\
\hline Shore type & $(1 / 5,1 / 4,1 / 3)$ & $(1,3,5)$ & $(1,1,1)$ & $(1 / 5,1 / 3,1)$ \\
\hline Earthquake & $(1 / 5,1 / 4,1 / 3)$ & $(3,4,5)$ & $(1,3,5)$ & $(1,1,1)$ \\
\hline Distance to shoreline & $(1,2,3)$ & $(1,1,1)$ & $(1,3,5)$ & $(1 / 5,1 / 4,1 / 3)$ \\
\hline Proposed area & $(1 / 3,1 / 2,1)$ & $(1 / 5,1 / 3,1)$ & $(1,1,1)$ & $(1 / 5,1 / 4,1 / 3)$ \\
\hline Land use & $(1,3,5)$ & $(3,4,5)$ & $(3,4,5)$ & $(1,1,1)$ \\
\hline
\end{tabular}


Table 3. contd....

\begin{tabular}{|c|c|c|c|c|}
\hline Goal & Shipping Activities & Flight Safety & Ecological Protection & Fish Resource \\
\hline Flight safety & $(3,5,7)$ & $(1,1,1)$ & $(1,3,5)$ & $(3,5,7)$ \\
\hline Ecological protection & $(1 / 5,1 / 3,1)$ & $(1 / 5,1 / 3,1)$ & $(1,1,1)$ & $(1,2,3)$ \\
\hline Fish resource & $(1 / 3,1 / 2,1)$ & $(1 / 7,1 / 5,1 / 3)$ & $(1 / 3,1 / 2,1)$ & $(1,1,1)$ \\
\hline
\end{tabular}

the local weights of sub-criteria are calculated as the results of Table 4.

Table 4. The Weights and $\lambda$ Value of Level Second Level for Weather and Marine Meteorology, Geology and Topography, Locations and Proposed Area and Human Behavior and Ecological Protection

\begin{tabular}{|c|c|c|}
\hline Goal & Weights & $\lambda$ value \\
\hline \hline Typhoon & $\mathrm{w}_{11}=0.55$ & 4.27 \\
\hline Thundershower & $\mathrm{w}_{12}=0.13$ & 4.16 \\
\hline Temperature & $\mathrm{w}_{13}=0.23$ & 4.24 \\
\hline Tide & $\mathrm{w}_{14}=0.10$ & 4.17 \\
\hline
\end{tabular}

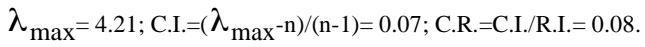

\begin{tabular}{|c|c|c|}
\hline Goal & Weights & $\lambda$ value \\
\hline \hline Wind power & $\mathrm{w}_{21}=0.57$ & 4.24 \\
\hline Geology & $\mathrm{w}_{22}=0.07$ & 4.18 \\
\hline Shore type & $\mathrm{w}_{23}=0.13$ & 4.19 \\
\hline Earthquake & $\mathrm{w}_{24}=0.23$ & 4.25 \\
\hline
\end{tabular}

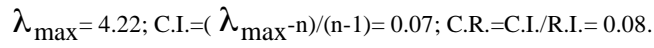

\begin{tabular}{|c|c|c|}
\hline Goal & Weights & $\lambda$ value \\
\hline \hline Water depth & $\mathrm{w}_{31}=0.17$ & 4.07 \\
\hline Distance to shoreline & $\mathrm{w}_{32}=0.21$ & 4.19 \\
\hline Proposed area & $\mathrm{w}_{33}=0.10$ & 4.11 \\
\hline Land use & $\mathrm{w}_{34}=0.51$ & 4.23 \\
\hline
\end{tabular}

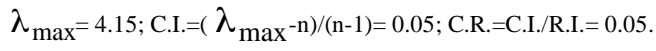

\begin{tabular}{|c|c|c|}
\hline Goal & Weights & $\lambda$ value \\
\hline \hline Shipping activities & $\mathrm{w}_{41}=0.19$ & 4.48 \\
\hline Flight safety & $\mathrm{w}_{42}=0.54$ & 4.21 \\
\hline Ecological protection & $\mathrm{w}_{43}=0.15$ & 4.23 \\
\hline Fish resource & $\mathrm{w}_{44}=0.10$ & 4.09 \\
\hline
\end{tabular}

$\lambda_{\text {max }}=4.25 ;$ C.I. $=\left(\lambda_{\left.\text {max }^{-n}\right) /(\mathrm{n}-1)=0.08 ; \text { C.R. }=\text { C.I. } / \text { R.I. }=0.09}\right.$.
Four comparison matrices at the second level have good consistency because all C.I. indexes are smaller than 1 . It should be noted that the two-dimensional fuzzy comparison matrices are always completely consistent.

The second level of hierarchy with respect to the upper level elements, the local fuzzy weights of the sub-criteria are shown from Figs. (3-6). In Fig. (3), we can found that typhoon is the most important factor comparing with thundershower, temperature and tide in the weather and marine meteorology. Above results implies that typhoon will damage the offshore wind mechanic, especial for Taiwan, because there are average three to seven typhoons or tropical storms each year.

As for the results of local fuzzy weight of the sub-criteria for geology and topography (Fig. (4)), it is found that the wind power (i.e., the energy can be generated) is greater than other factors. In other words, the greater wind energy was regarded as the greater contributions to power supplies. In general, the minimum allowable value adopts the wind potential of wind speeds greater than $4 \mathrm{~m} / \mathrm{s}$. As seen in the figures, the earthquake also affects the appropriate sites of offshore wind farm in Taiwan. Taiwan is an island, which is located in a sub-duction zone between Philippine Sea and Eurasian Plates, it has been often attacked by earthquake in East Asia.

At the level of hierarchy with locations and proposed area (Fig. (5)), we can see the land use is the most important factor, because the types of land use whether commercial or private would affect the construction of offshore wind farms. If there is a large concentration of population, building an obstruction to block water views is extremely undesirable. Thus, lesser population density, lesser disputes would result and approvals are readily granted. In addition, the size of the proposed development areas will also affect the position of the offshore wind farms and the size and numbers of wind turbines. This will also affect the operation and maintenance cost. Fig. (6) shows that flight safety is more important than shipping activities, ecological protection and fish resource in the level of human behavior and ecological protection. Because of the economic development would be globalized. The logistics are facing the strong international competitions, tourisms and the military requirements. The importance of the communications and transportation increases day by day and the safety of aircraft are paid great attention. Therefore, the flight safety is key factor for offshore wind farms in Taiwan. The results of the global weights from the fuzzy AHP method are shown in Fig. (7). It is observed that the 
wind power is the most important factor for an offshore wind farm site selection in Taiwan.

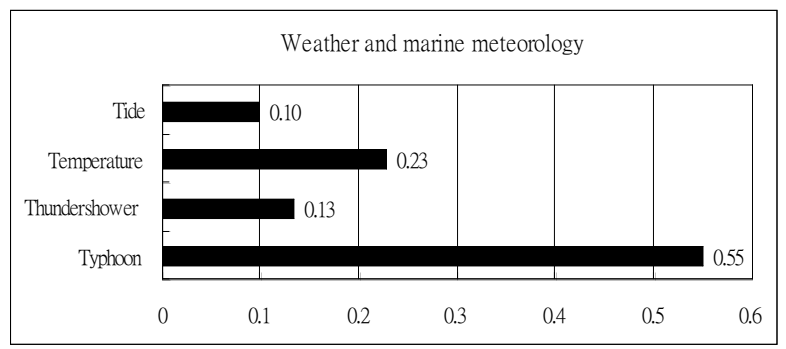

Fig. (3). Local fuzzy weight of the sub-criteria for weather and marine meteorology.

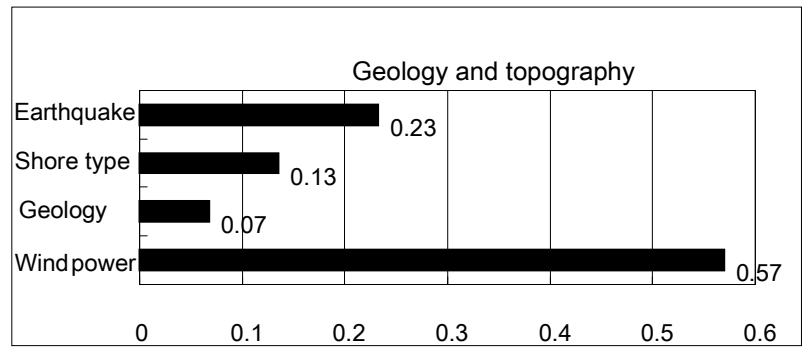

Fig. (4). Local fuzzy weight of the sub-criteria for geology and topography.

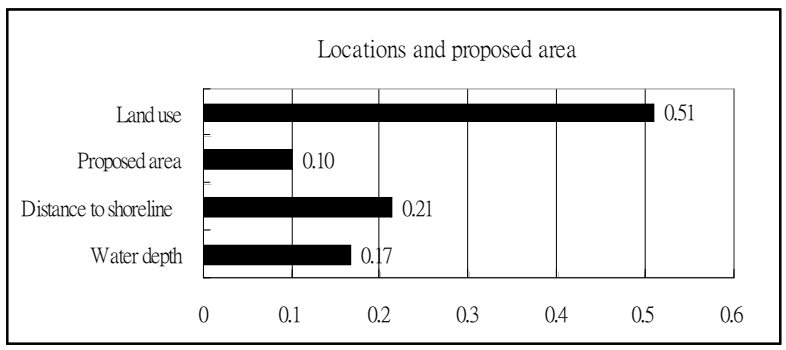

Fig. (5). Local fuzzy weight of the sub-criteria for locations and proposed area.

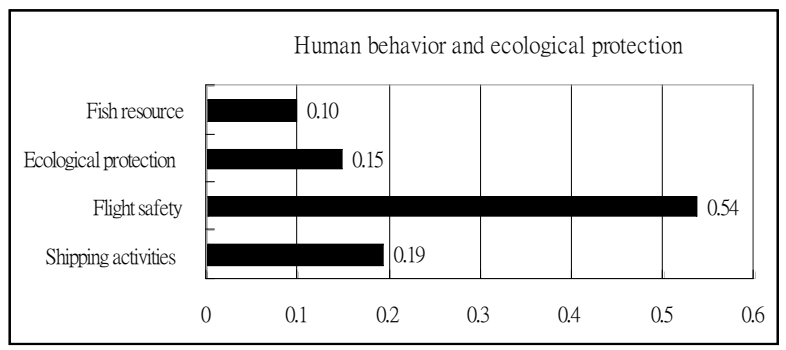

Fig. (6). Local fuzzy weight of the sub-criteria for human behavior and ecological protection.

\section{ASSESSMENT OF OWES SITES IN TAIWAN}

To assess possible sites of offshore wind energy in Taiwan, we establish a set of selection criteria (Table 5). Based on the proposed OWES sites in Taiwan, the major criteria for the selection of offshore wind farms are summarized here:

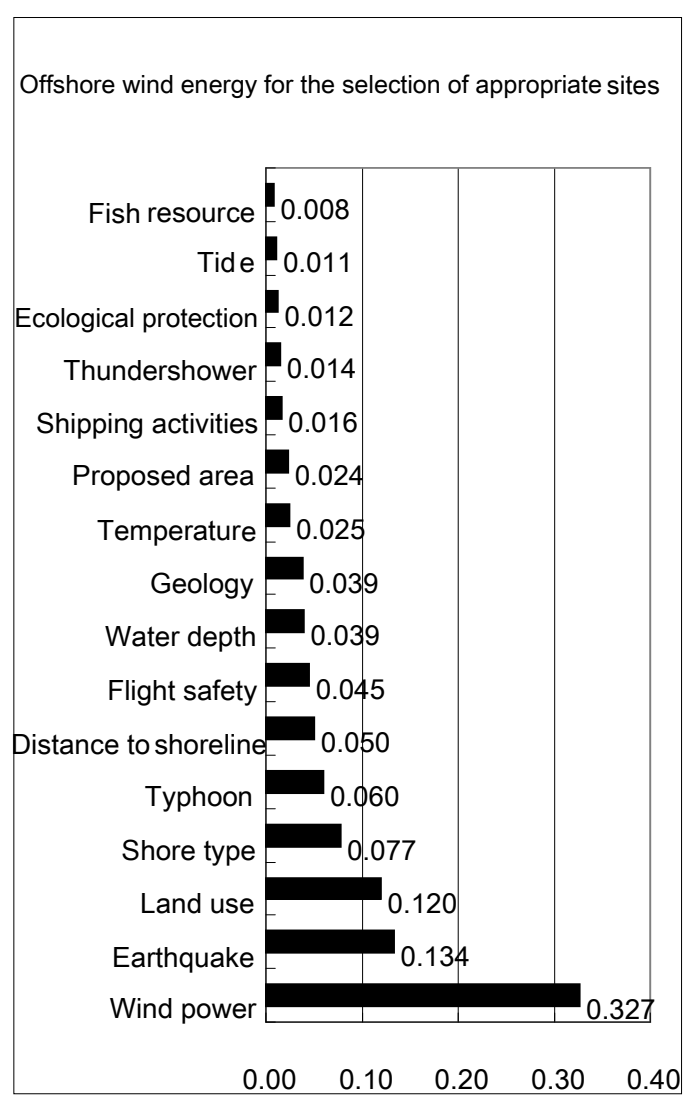

Fig. (7). The global fuzzy weights of Fuzzy AHP.

\section{Wind Power}

Wind power is the conversion of wind energy into more useful forms, usually electricity using wind turbines. Wind energy is ample, renewable, widely distributed, clean, and mitigates the greenhouse effect. At the end of 2008, worldwide nameplate capacity of wind-powered generators was 121.2 gigawatts (GW). In 2008, wind power produced about $1.5 \%$ of worldwide electricity usage and is growing rapidly, having doubled in the three years between 2005 and 2008.

Wind Speed is the dominant criterion for the selection of sites, as it is the main resources for OWE. The Energy Commission of the Republic of China (ECROC) has estimated that there are land areas of 2070 and $8046 \mathrm{~km}$ with mean wind speeds greater than 5 and $4 \mathrm{~m} / \mathrm{s}$ reach, respectively. Areas with annual mean wind speeds of more than 4 $\mathrm{m} / \mathrm{s}$ already possess the technical potential of exploiting wind energy [13]. Wind energy possesses a technical potential of about $4000 \mathrm{MW}$ in Taiwan. This would be capable of generating some 10TWh of electricity annually, covering about $3.3 \%$ of the entire electricity demand by 2020 in Taiwan.

\section{Earthquake}

Taiwan has a high degree of seismic activity due to its location at the junction of the Manila Trench and the Ryukyu Trench along the west side of the Philippine Sea plate. In 2005, 558 earthquakes were recorded, including 167 larger earthquakes reported by the Central Weather Bureau (CWB), 
Table 5. General Selection Criteria

\begin{tabular}{|c|c|c|c|}
\hline \multicolumn{2}{|l|}{ Criteria } & \multirow{2}{*}{$\begin{array}{l}\text { Score } \\
2\end{array}$} & \multirow[t]{2}{*}{ Note } \\
\hline Wind power & $<200 \mathrm{~W} / \mathrm{m}^{2}$ & & \\
\hline & $<400 \mathrm{~W} / \mathrm{m}^{2}$ & 0 & \\
\hline \multirow{2}{*}{ Earthquake } & & 1 & 7-9 the Richter magnitude \\
\hline & & 2 & $>10$ the Richter magnitude \\
\hline Land use & Small & 1 & $<50$ turbines \\
\hline \multirow[t]{3}{*}{ Shore type } & & 0 & Sandsore \\
\hline & & 1 & Sandsore and partical rock \\
\hline & & 2 & Partical rock \\
\hline \multirow[t]{3}{*}{ Typhoon } & 40 & 0 & The occurring number of invading typhoons in 1898 2008 \\
\hline & 80 & 1 & \\
\hline & 120 & 2 & \\
\hline Distance to shoreline $(\mathrm{km})$ & $<3$ & 3 & Too close to the shoreline \\
\hline \multirow{2}{*}{ Area of army } & & 1 & Non-important area of army \\
\hline & & 0 & No area of army \\
\hline \multirow[t]{5}{*}{ Water depth (m) } & $<1 \mathrm{~m}$ & 3 & Extremely large visual impact \\
\hline & $2-5 \mathrm{~m}$ & 2 & Large visual impact \\
\hline & $5-9 m$ & 1 & Moderate visual impact \\
\hline & $10-20 \mathrm{~m}$ & -1 & Small visual impact \\
\hline & $>20 \mathrm{~m}$ & -2 & No visual impact, but high cost \\
\hline
\end{tabular}

Total score

Rank (1, 2, 3 etc.)

Overall sensitivity (prefer, med, high).

with only 3 earthquakes registering a magnitude larger than 6 on the Richter scale occurred in the offshore area of eastern Taiwan. The occurrence of earthquakes will not only damage the construction buildings, but also destroy the residents' properties and lives. For example, the earthquake with Richter magnitude of 7.3 occurred at Chi-Chi City on September 21, 1999 has been recognized as the most serious disaster by public concerns in Taiwan. During the earthquake, numerous civil structures, such as buildings, highway embankments, retaining structures etc., have been damaged or completely destroyed. Therefore, the selection of the offshore wind farms for offshore area of Taiwan under earthquake threat is needed to be examined. 


\section{Land Use}

The types of land use whether commercial or private would affects the construction of offshore wind farms. If there is a large concentration of population, building an obstruction to block water views is extremely undesirable. Thus, lesser concentration of people, lesser disputes would result and approvals are readily granted. Problems associated with during and after construction can affect the local population. Job creation and social aspects need to be addressed, too.

In addition, the levels of boating and recreational activities also lead to the complications to the construction of offshore wind farms. If the selected area has active boating and recreational activities, public disapproval would results. Public anguish and rallies in many instances dictate the approval of government plans. Due to these difficulties, leisure should be included as part of the criteria. As for the size of the proposed development areas, we know the size will affect the position of the offshore wind farms and numbers of wind turbines. This will also affect the operation and maintenance cost.

\section{Shore Type}

Taiwan Island is situated between the continental shelf of China and the open sea of the Pacific Ocean. Typical marine geographical formations of Taiwan Island show that its east coast facing the Pacific Ocean consists of rocks and gravel with rather steep bottom slopes up to the order of 1 in 10 . However, the west coast along the Taiwan Strait consists of finer sands with much milder slopes of about the order of 1 in 200-500.

\section{Typhoon}

Typhoon generates often subject to severe sea states during the summer in either the South China Sea or the Northwest Pacific Ocean near the Philippine islands, resulting in extensive loss of life and property in Taiwan. According to Taiwan's Central Weather Bureau (CWB), there were three to seven typhoons or tropical storms each year affecting Taiwan in the past 7 years. There were 436 typhoons for the years 1898-2008. Most of typhoons have a maximum wind speed greater than $25 \mathrm{~m} / \mathrm{s}$. The strength of wind speed will affect the safety of wind power.

\section{Water Depth and Distance to Shoreline}

Water depth and distance to shoreline are two extremely important criteria for the selection of offshore wind farms.
Most current offshore wind turbines are installed in shallow water with the form of monopiles and gravity foundations. It is well known that wind speed will a sharp increase with distance to shore. Sitting positions also improve with distance from shore, as there are more variable high wind sites with less visual impacts and competing use for the seabed. These will gradually attract developers to deep water.

That is, the substructures of wind farms will move from current mono-piles and gravity foundations in shallow water, to floating structure in deep water. However, the costs of offshore wind farms will increase as water depth increases.

\section{Flight Safety}

Facing the multifaceted challenges of global environment, the Ministry of National Defense of R.O.C. proposed their defense policy called war prevention and homeland defence. Then, the main purpose of R.O.C. armed force's military buildup. In the other word, maintaining the stability of Taiwan Strait is very important. Based on the war and homeland defence, the position of the offshore wind farms should take into account the military concerns.

From the result by Fuzzy AHP, we can obtain the importance sequence factors that may affect the offshore wind energy, including for the power, earthquakes, land use, shore type, typhoon, distance to shoreline, flight safety and Water depth.

Following a series of estimate principle for the potential of offshore wind energy in Australia [6], we select five sites (Taichung, Changhua, Chiayi, Yilan and Hualien) around Taiwan (Fig. (8)) to assess a preferred site for offshore wind energy. And, the ranking scores for all factors will be given and summarized in Table 6. For instance, when the wind power is less than $200 \mathrm{~W} / \mathrm{m}^{2}$, the score is given by 2 , but the wind power is bigger than $400 \mathrm{~W} / \mathrm{m}^{2}$ is given for 0 .

As mentioned by Jeng [6], a smaller number represents more faviour for the offshore wind energy. As shown in Table 6, nearby coastal areas of Changhua will be a preferred site for offshore wind energy in Taiwan (Fig. (8)).

\section{CONCLUSIONS}

Determining the importance sequence and identifying the key factors for the selection of OWES sites is a challenge task In this study, we applied the Fuzzy Analytic Hierarchy Process (Fuzzy AHP) to determine the importance sequence and find out the key success factors of offshore wind energy. Though there are many factors that may affect the offshore wind energy, this paper concluded that only eight factors,

Table 6. Assessment of Five Sites for OWE in Taiwan

\begin{tabular}{|c|c|c|c|c|c|}
\hline Nearby Coastal Areas & Taichung & Changhua & Chiayi & Yilan & 12 \\
\hline \hline Total score & 7 & 5 & 9 & 4 & 5 \\
\hline Rank & 2 & 1 & 3 & high & med \\
\hline overall sensitivity & high & Prefer & med \\
\hline
\end{tabular}


including the wind power, earthquakes, land use, shore type, typhoon, distance to shoreline, flight safety and water depth. With a set of criteria based on these eight factors, five different sites in Taiwan will be assessing to select an appropriate site for the first offshore wind farms. From the results, the Changhua coastal area obtains a smaller number and represents more potential for the development the first offshore wind farms in Taiwan.

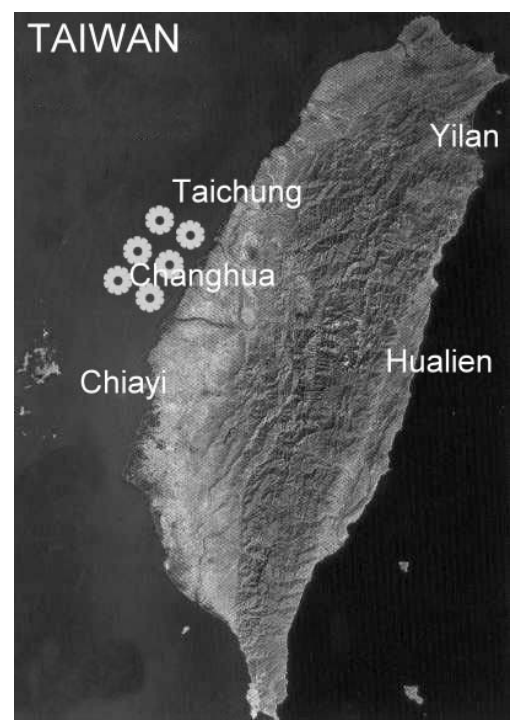

\section{ACKNOWLEDGEMENTS}

This work is supported by the National Science Council, Taiwan, R.O.C. under Grant No. NSC 96-2221-E-426-010.

\section{REFERENCES}

[1] R. J. Barthelmie, "Meteorological aspects of offshore wind energy: Observatiosn from the Vindey wind farm", J. Wind Eng. Industrial Aerodyn., vol. 62, pp. 191, 1996.

[2] A. Lavagnini, "Estimating wind energy potential offshore in Mediterranean area", Wind Eng., vol. 6,pp. 23, 2003.

[3] W. Musial, "Energy from offshore wind", Offshore Technology Conference, Houston, USA, OTC18355, 2006.

[4] The Bureau of Energy, White paper on energy policy (in Chinese), Available from http://www.moeaboe.gov.tw/, 2006.

[5] Energy Statistic Handbook, Bureau of energy MOEA, ROC. 2004.

[6] D. S. Jeng, "The potential of offshore wind energy in Australia", Offshore Technology Conference, OTC18578, 2007.

[7] D. S. Jeng, and Y. Zheng, Energy from offshore wind: An overview, In Water wind art and debate-how environmental concerns impact on disciplinary research (edited by Gavin Birch), pp. 244-279, 2007.

[8] T. L. Saaty, The Analytic Hierarchy Process, New York: McGrawHill, 1980.

[9] T. L. Saaty, Multicriteria Decision Making: The Analytic Hierarchy Process, RWS Publications, Pittsburgh PA, 1988.

[10] H. Deng, "Multicriteria analysis with fuzzy pairwise comparisons", Int. J. Approxi Reason, vol. 21, pp. 215-231, 1999.

[11] L. Mikhailov, "A fuzzy programming method for deriving priorities in the analytic hierarchy process", J. Operat Res. Soc., vol. 51, pp. 341-349, 2000.

[12] J. J. Buckley, "Fuzzy hierarchical analysis", Fuzzy Sets Syst., vol. 17, pp. 233-247, 1985.

[13] M. Kaltschmitt, and A. Wiese, Technical energy potential, replaceable end and primary energy equivalents and costs of renewable energy sources in Germany, pp. 41-64, 1994.

Fig. (8). Proposed sites for offshore wind energy in Taiwan.

(C) Tsung-Lin Lee; Licensee Bentham Open.

This is an open access article licensed under the terms of the Creative Commons Attribution Non-Commercial License (http://creativecommons.org/licenses/_by-nc/3.0/) which permits unrestricted, non-commercial use, distribution and reproduction in any medium, provided the work is properly cited. 